\title{
Normalising and Neutralising Offending - The Influence of Health and Safety Regulation
}

\author{
Emily Schindeler ${ }^{*}$ and Janet Ransley ${ }^{\dagger}$
}

\begin{abstract}
One form of corporate malfeasance involves violation of workers' rights to a safe workplace. This article complements the dominant functionalist discourse concerned with defining, categorising and establishing antecedent conditions for psychological injury (and attendant physical health and social harm) arising from mistreatment at work. Drawing from claims heard in Australian courts and tribunals, this analysis examines the counterarguments presented by respondents in such cases. This preliminary evidence suggests that the normalisation and neutralisation of offending behaviours provides a justification for failing to deliver a safe work environment and for exacerbating injury when it has occurred. Further, the framing of regulation has enabled this pattern of neutralisation of offending and denial of justice for victims. This article calls for a re-examination of the way in which victimisation has been problematised and the consequent implications for prevention.
\end{abstract}

Keywords: neutralisation - normalisation - regulation - corporate malfeasance procedural justice - workplace abuse - health and safety

\section{Introduction}

The scope and volume of academic, practitioner and regulatory commentary on psychological injury caused by abuse at work has grown exponentially in the last decade. Whether the offending behaviour is termed 'harassing', 'threatening', 'intimidation, 'mobbing' or 'bullying', research and the accompanying narrative has largely adopted a functionalist approach. Consistent with the functionalist perspective, academic researchers, regulators, and policy makers have devoted considerable effort to defining and categorising indicative behaviours, qualities of organisational culture and management processes and to establishing antecedent conditions that enable abuse to occur. The prevailing portrayal has characterised such abuse as a form of interpersonal violence influenced by aspects of the work environment.

Lecturer, School of Criminology and Criminal Justice, Griffith University, 176 Messines Ridge Road, Mt Gravatt Q1d 4122 Australia. Email: e.schindeler@griffith.edu.au.

$\dagger \quad$ Head of School of Criminology and Criminal Justice, Griffith University. Email: j.ransley@griffith.edu.au. 
In Australia, health and safety legislation has been the primary regulatory mechanism intended to protect employees from avoidable injury. As a 'responsive regulation' model, this framework relies upon the premise that there is an organisational commitment to, and systems of governance consistent with, such protections and the regulatory requirements. All employers are obligated to adopt processes designed to predict and trigger appropriate actions to minimise or manage risks to the health and safety of workers. This regulatory approach, which presumes a motivation to prevent abusive behaviours, fails to recognise that organisational benefits may accrue when abusive behaviour is reframed as a justifiable part of a legitimate management process.

While the need to take steps to deter and respond to psychological abuse within the context of domestic violence has achieved substantial international recognition, such abuse within the work environment has proven to be substantially more contentious. This may reflect the legitimation of abusive behaviour as a convenient fit with the political and regulatory perspectives in which health and safety are perceived largely as economic and productivity matters. This perception is mirrored by growing concern with the escalating annual cost of psychosocial and related health injury arising from abusive behaviour at work. The Australian Productivity Commission (2010) estimated that these costs may exceed A $\$ 6$ billion and Giga, Hoel and Lewis (2008) projected that annual costs in Great Britain would exceed $£ 13.75$ billion. This includes substantial costs to employers as well as the public purse. In contrast, individual health, social, professional and financial costs of such injury are excluded from regulatory compliance and enforcement processes.

This article raises the question whether the regulatory regime is able to effectively reduce offending when compliance and enforcement are predicated on principles of motivated selfregulation and rely upon management processes as the vehicle of prevention. We suggest that an alternative view, which situates the response to offending in the frame of procedural justice and, accordingly, as a form of corporate malfeasance, could enhance the potential for more effective and enduring prevention. Consistent with Tyler (1989), Hinds and Murphy (2007) and Thibaut and Walker (1975), we use the term 'procedural justice' to describe the processes used in decision making, the perceived fairness of such processes and the manner in which authority is exercised. We illustrate by example how the 'escape hatch' set out in regulation provides an expedient defence against claims of culpability or liability. Ultimately this means that the effectiveness of regulation, compliance and enforcement remains largely unpredictable and the capacity to normalise and neutralise offending behaviour is enabled.

We begin by describing critical features of the current approach to health and safety regulation in Australia, including the language and principles that shape the structure and processes intended to provide direction as to the responsibilities of the organisation, irrespective of sector, to protect those employed. This is followed by a discussion of the discursive practice that enables the normalisation and neutralisation of abusive behaviour resulting in injury to mental and physical health. We then set out the methodology and findings from the review of litigated cases involving claims of these injuries. Finally, discussion focuses on the benefits of reframing such offending as a form of corporate malfeasance enabled by procedural injustice in order to achieve more effective compliance and prevention.

\section{Regulating health and safety and procedural justice}

In Australia, work health and safety legislation is adopted and administered by individual national, state and territorial regulators. A feature of the national regulatory reform agenda 
has been adoption of a harmonised approach to such regulation. With the exception of the States of Western Australia and Victoria, the Commonwealth, state and territory legislation shares a common basis in the Model Work Health and Safety Act 2011. Further, the 'National Compliance and Enforcement Policy' adopted by the Workplace Relations Ministers' Council in 2011 has been agreed by all regulators across jurisdictions. As a consequence, the Australian work health and safety regime, irrespective of jurisdiction, relies upon the core principles of risk-based responsive regulation. Underpinning this approach is a central commitment to organisational self-regulation. Accordingly, methods of promoting compliance are based on Ayres and Braithwaite's (1992) pyramid model. This means compliance and enforcement should only escalate from the bottom of a pyramid of potential responses to increasing sanctions where compliance cannot otherwise be achieved. In short, it is assumed that organisations will voluntarily comply with regulatory expectations on the basis of self-interest and with the benefit of advisory support from the regulator. Despite efforts by regulators to encourage awareness and offer management tools, failure to comply may be a consequence of any number of factors, including, for example, a failure to realise the risk or costs, a lack of good management practice, or a general poor engagement with workplace health and safety matters.

Consistent with this emphasis on self-regulation, regulators view organisational policies and procedures as reflective of the quality of compliance with requirements to protect worker health and safety. Embedded within this model is the pre-eminent concern with the identification and management of risk. A consequence of this concentration on process and documentation, rather than outcomes, is that regulatory enforcement becomes largely a technical matter in which assessing or determining non-compliance does not necessarily lead to a change in attitude or performance and is not structured to provide any specific outcome for a victim (Black and Baldwin 2010).

The prioritisation of risks for employers and regulators is influenced by the broader environment in which the regulation operates. As noted by Hawkins (1990), the priorities and decision to enforce, or how to enforce, are ultimately determined on the basis of a moral and political commitment or ambivalence to the risk and the problem. When the nature of risk or harm is viewed from the perspective of normative expectations, responding to violations that involve health, rather than safety, can become particularly contentious. As a consequence, Hawkins (1990) argues that the regulatory response to such risk or harm is more likely to rely on negotiated compliance than on sanction of any breach. This observation is validated by the Australian experience, where the regulators have not applied any serious sanctions for abuse of workers causing psychological injury except in cases that have also involved death or serious physical injury. This indicates not only the relative lack of import ascribed to abuse causing psychological injury - it equally could be interpreted by employers as a 'get out of jail free' card for breaches.

\section{Procedural justice}

Inherent in the construction of responsive regulation is the matter of ensuring procedural justice. This includes the extent to which the organisation perceives the regulatory relationship as being procedurally just, the extent to which the individual perceives regulatory intervention in dealing with complaints of victimisation is just, and the extent to which the regulator considers procedural justice in assessing compliance with the terms and intent of regulation. These different views of procedural justice are described by Konovsky (2010) in terms of 'objective justice' (referring to actual or factual justice) and 'subjective justice' (referring to perceptions of justice as delivering fairness). As suggested by Folger (1987), if procedures are 
viewed as flawed or improper, the outcomes will be similarly perceived as being unjust. This is particularly the case when a belief that misbehaviour of another party is involved.

Folger further argues that an element of expectation is implicit in subjective procedural justice. Where formal procedures fail to meet expectations or to provide predictable and consistent decision making, it is likely that a conclusion will be drawn that procedural justice has not been achieved. This may involve defective procedural design or flawed implementation, whether by intent or error.

Therefore, the separation of the regulator's actions in assessing or promoting organisational compliance with the responsibility for protecting health and safety from any outcome for the victim is procedurally flawed by design. Even where it has been found that there has been a systemic failure to prevent or respond to abuse, the regulatory regime offers no practical outcome for the victim. This in turn is likely to lead to an individual's perception of a fundamentally unjust process, leaving the victim with the onus of responsibility to pursue procedural justice from an external court, commission or tribunal.

\section{Duty of care, risk and reasonability}

The Model Work Health and Safety Act 2011 ('MWHS Act') sets out the duty of care responsibilities of employers and workers, and the actions required to ensure compliance with such obligations. Under the MWHS Act, a person conducting a business (irrespective of sector) and each worker is responsible for protecting his or her own health and safety as well as that of others within the workplace. Section 17 of the $M W H S$ Act requires that an employer take steps to eliminate or minimise risks to health and safety as far as practicable. Sections 27 and 28 allocate responsibilities for health and safety to officers and workers. The requirements to identify and minimise risk are framed by the concept of 'reasonably practicable' with reference to likelihood and severity of harm that may emanate from the risk. Importantly, as noted by Black and Baldwin (2010), risk-based frameworks are not neutral; rather, they are a reflection of the balance of risks the employing organisation is willing to accept. This becomes critical in regard to the way in which mechanisms described as management tools have been employed for neutralising what might otherwise be considered abusive and harming behaviours. This may involve, for example, using processes intended to respond to allegations but which inadequately address injury, deflect claims of harm, or deny liability.

Provisions of the MWHS Act in conjunction with the National Compliance and Enforcement Policy are critical determinants of the likelihood, extent and severity of sanctions that may be applied by regulators in the case of employer breaches of duty of care obligations. The MWHS Act establishes three categories of offence relevant to this duty (and enforcement processes): Category 1 Reckless Conduct; Category 2 Failure to Comply with Health and Safety Duty (and the failure exposes an individual to a risk of death or serious injury or illness); and Category 3 Failure to Comply with a Health and Safety Duty. The decision to prosecute is linked to Category 1 offences. Similarly, the National Compliance and Enforcement Policy has a primary emphasis on monitoring and deterrence, despite acknowledgement that prosecution should be pursued where there is public interest (given the increasing number of successful compensation claims and media reports would suggest that public interest is relevant) and support by the Director of Public Prosecutions.

Safe Work Australia reported in May 2014 that compensation claims associated with psychological injury caused by varying forms of abusive behaviour were second only to work stress claims in the period 2010-11. Further, it found that the increase in such claims was not mirrored with respect to claims for mental stress, which consistently declined over the past decade. Given the patterns of claims for compensation for psychological injury, the interface 
with the regulatory regime is relevant. Across jurisdictions, workers' compensation arrangements operate independently from work health and safety regulation. Successful claims require a claimant to demonstrate that an injury or disease has occurred, that it is a consequence of work-related events and that is not the consequence of reasonable management undertaken in a reasonable manner. As will be demonstrated in the analysis of compensation claim cases reviewed in the current study, these latter requirements are contentious, and particularly with regard to establishing common understandings of what constitutes 'reasonable'. As noted by Pearce (2006), the terms 'reasonable' and 'arising out of' are purposefully vague, enabling considerable flexibility in determining outcomes. This led to Pearce's conclusion that 'this is not a field of law where the language used in an Act will guarantee an outcome' (2014:3). Nonetheless, there is a high degree of consistency between the compensation criteria and regulatory provisions associated with risk assessment, the employment of management tools such as performance management, and benchmarks of reasonable foreseeability.

\section{Enabling discourse: Normalisation and neutralisation}

The evolution of theoretical approaches to explaining how behaviours that might otherwise be condemned can be rendered acceptable has its initial grounding in the work of Edwin Sutherland. Sutherland (1949) suggested that white collar crime occurs when workers learn the motivations and rationales for offending behaviour and such learning outweighs the reasoning behind compliance with the law. Further, he argued that this learning involves a mix of the mechanical or operational techniques for offending and the intellectual techniques or rationalities that enable such behaviour. Sykes and Matza (1957) later presented a theory of neutralisation whereby behaviour that would otherwise be constrained by an individual's moral and normative beliefs is enabled by the adoption of a range of justifications. Described as techniques of neutralisation, Sykes and Matza suggested that typical justifications include:

- denial of responsibility;

- denial of injury;

- denial of the victim;

- condemnation of condemners; and

- appeal to higher loyalties.

Subsequent refinements and extensions of the neutralisation theory (for example, Klocker 1974; Minor 1981) have seen neutralisation as enabling offending behaviour across a variety of contexts, both individual and collective. Bandura et al (1996) added to understanding by suggesting that that there were four mechanisms that enabled offenders to ignore those considerations which guide self-regulation and deter offending. These mechanisms included:

- diffusion and displacement of responsibility;

- misrepresenting or disregarding the injury; or

- denigrating the victim.

Such rationalities then allow organisations and individuals to render as acceptable behaviours that would otherwise be seen as objectionable. 
Arguably, the process of rationalisation or adoption of justifications that override normative values does not occur in a vacuum. As noted by Yeager and Reed (1998:887), 'motives are the linguistically and socially structured reasons for human action, any full explanation of criminal or other deviant action must theorize them carefully as fundamental to - and in - the causal nexus'. Further, Yeager and Reed argue that both motivation and opportunity emerge from a need to negotiate the meanings, relationships and roles within the organisational setting. Offending behaviour within the organisation may form a means by which to fit in with and respond to organisational meanings and imperatives. This suggests that the view of offending within the organisational setting is inadequately explained as simply a consequence of an individual's lack of self-control or deviant socialisation. As Yeager and Reed suggest, motivation and opportunity are 'social constructions, negotiated between individuals interacting in specific institutional settings - as typically - morally justified options and reasons for choosing them' (1998:892). The conclusion is that offending behaviour, whether or not considered criminal, can be viewed as being motivated by both selfinterest and organisational interest; that is, an institutionally accepted, if not openly acknowledged, view that such behaviours or actions can be ethically justified.

Piquero, Tibbetts and Blankenship (2005) similarly concluded that the everyday practices within an organisation can effectively undermine the values and ethical standards of individuals such that they may behave inconsistent with the moral and norms of behaviour that they practise outside that context. Organisational feedback reinforces particular forms of behaviour by providing justifications or excuses for what otherwise might be labelled as abusive but is an organisationally accepted form of offending. Nelson and Lambert (2001) summarised this process by describing how aligning actions and motives to routine practices enables the neutralisation process: 'These techniques provided a semantic for the potentially labelled deviant by furnishing exculpatory motives for engaging in disreputable behaviour' (2001:86).

As observed by Lutgen-Sandvik and Tracy (2011), organisations can disguise and then validate abusive behaviour as legitimate management action. In a review of studies involving bullying, they identified a pattern of discursive practices designed to counter allegations of mistreatment. These include, for example, disqualification (reducing the credibility of the victim), individualising (blaming the complainant) and normalising the behaviour as a means of silencing discussion. Nelson and Lambert (2001) similarly found in a study of bullying behaviour in tertiary institutions that, rather than denying responsibility for misbehaviour, an alternative narrative was adopted in which actions were presented simply as part of normal practice. Further, they suggest that by aligning actions and motives to routine practices it was possible to establish 'exculpatory motives for engaging in disreputable behaviour' (2001:86).

Illustrative weight is given to this argument through case studies examining the willingness or reticence of bystanders to take action (D'Cruz and Noronha 2011; Pershing 2003) and perceptions of accused perpetrators (Jenkins et al 2012). For example, Pershing (2003:172) found that there was a disinclination to report peers' misconduct given any clear organisational incentives to do so. Alternative explanations for a reticence to act included an acceptance of the rationales of the wrong-doer, a fear of organisational responses and a belief that blame should be ascribed to those in greater positions of power. Similarly, D'Cruz and Noronha (2011) reported that a combination of organisational processes and managerial values that emphasise employer interests overshadowed the weight of friendships and lent legitimacy to mistreatment. Jenkins et al (2012) similarly found a pattern of denial of harm and responsibility among those accused of abuse on the basis of defining their actions as consistent with management practice within the organisational culture. 
The argument was well summarised by Zoghbi-Manrique-de Lara (2010) in observing that 'organizations embody a number of processes through which employees are socialized into accepted and standardized ways of thinking and acting that can constitute a kind of organizational moral microcosm' (2010:414). This includes the capacity to normalise a way of contorting and viewing condemnable actions as acceptable.

\section{Defending claims and neutralisations}

The Australian High Court, federal and state supreme courts, magistrates courts and specialist tribunals adjudicate claims and appeals involving psychosocial injury as a consequence of abuse at work. To identify relevant cases, a comprehensive search was made of the AustLII database, inclusive of all Australian jurisdictions. Search terms included: threat, intimidation, bully, psychosocial injury, harassment, psychiatric injury, depression, assault, and aggression. Cases involving primary claims of physical injury, sexual harassment or where the violence was perpetrated by an individual from outside the organisation were excluded. A review of the 77 cases identified in this search revealed a pattern of arguments involving organisational claims of non-liability and complainant claims of organisational culpability in causing psychological or psychiatric injury. In addition, 54 cases heard by the Australian Industrial Relations Commission and Fair Work Commission involving similar claims underpinning constructive and unfair dismissals over the 2007 to 2011 period implicated procedural injustice as a significant issue. Analysis of these cases provides a window through which to view the way in which organisations have employed the explicit and implicit components of the regulatory framework to deflect culpability or liability for documented psychological injury.

\section{Adjudicating claims of psychological injury}

Various courts, commissions and tribunals heard 49 cases involving claims of psychological injury caused by workplace abuse over the five-year period 2007-12. Complainants consistently argued that the employer was negligent in failing to provide a safe work environment and system of work and/or that there was a failure to take effective steps in response to injurious behaviour. Courts found evidence of negligence in seven out of 10 claims involving a failure to provide a safe work place or system of work. In the nine claims involving a failure to take corrective steps in response to injuries, judicial determinations found that organisations had failed to take reasonable responsive action in each of the cases. Collectively across these cases it was found that organisational procedures exacerbated and were part of an ongoing abusive situation.

The explanatory justifications presented by employer organisations in disputing liability or culpability are indicative of the neutralisation techniques adopted. The rationalities that have been employed have been designed to deflect responsibility by allocation of blame or denial of injury to the complainant or to neutralise liability by presenting events as being unexceptional, and part of organisational processes. These arguments reflect how organisations have sought to present behaviours or actions as acceptable. Table 1 summarises the key claims and determinations for cases involving work-based psychological injury and disease. Notably, despite the repeated argument that actions were not abusive, but rather were reasonable management actions, this defence proved to have a poor record of success. It was also argued that, despite the requirement to assess and minimise the likelihood of risk, the psychological injury was not foreseeable. Given that this approach to neutralisation was only successful in approximately half of the occasions it was presented, foreseeability remains 
contentious. Finally, despite the small sample number (only 5 or 10 per cent of total cases), the denial of injury or denial of material responsibility for injury (a classical means of neutralising responsibility) was also evident in these cases.

\section{Table 1: Key issues and determinations for cases involving psychological injury and disease}

\begin{tabular}{lcc}
\hline Key claims & $\begin{array}{c}\text { Number of } \\
\text { cases }\end{array}$ & $\begin{array}{c}\text { Percentage } \\
\text { upheld }\end{array}$ \\
\hline $\begin{array}{l}\text { Organisation defence: Exclusion for reasonable } \\
\text { management administrative action taken in a reasonable } \\
\text { manner }\end{array}$ & 11 & 18 \\
$\begin{array}{l}\text { Organisation defence: Lack of foreseeability of injury } \\
\text { occurring }\end{array}$ & 95 \\
$\begin{array}{l}\text { Organisation defence: No demonstrable injury or } \\
\text { employment not a material contributor to injury/disease }\end{array}$ & 5 & 60 \\
$\begin{array}{l}\text { Basis of claim of liability: Negligence in failing to provide } \\
\text { a safe work environment and system of work }\end{array}$ & 10 & 70 \\
$\begin{array}{l}\text { Basis of claim of liability: Failure to take reasonable action } \\
\text { in response to injurious behaviours }\end{array}$ & 9 & 100 \\
\hline
\end{tabular}

Distinct from responsibilities under the MWHS Act, employer-funded subscriptions to workers' compensation insurance are mandated in Australia. Some jurisdictions offer public (government-operated) schemes, while in others private insurers operate with endorsement by regulators. In addition to defending claims heard in the relevant courts and industrial tribunals, organisations can challenge a claim for or decision to grant or deny compensation. Each of the cases identified over the eight-year period to 2013 involved claims of major psychological injury materially attributable to abusive work-related behaviours and events. This includes claims of a lack of procedural justice, intimidation, bullying, harassment and victimisation. Appeals against compensation claims focused on the reasons why such claims should be excluded, while rarely challenging the medical evidence of injury. In fact, only about onequarter of cases had the actual injury challenged. In contrast, arguments were primarily concerned with the reasons why such injury should be excluded from compensation. By analysing the defences against compensation, a recurring pattern of neutralising arguments is evident.

As can be seen in Table 2, more than half the cases were successful where the defence was based on 'reasonable action [that] had been taken in a reasonable way'. Similar results were found when the defence was based upon denying employment as a material contributor to the injury. This means that the employer unsuccessfully sought to evade liability by displacing or diffusing responsibility in combination with allocating blame onto the complainant. 
Table 2: Opposing compensation: Defending psychological injury/disease

\begin{tabular}{lcc}
\hline Key claims & $\begin{array}{c}\text { Number } \\
\text { of cases }\end{array}$ & $\begin{array}{c}\text { Percentage } \\
\text { upheld }\end{array}$ \\
\hline $\begin{array}{l}\text { Exclusion claimed: } \\
\text { No liability: Due to reasonable management/administrative } \\
\text { action taken in a reasonable manner }\end{array}$ & 56 \\
$\begin{array}{l}\text { Exclusion claimed: } \\
\text { No liability: Exclusion for failure to obtain a benefit }\end{array}$ & 2 & 0 \\
$\begin{array}{l}\text { Exclusion claimed: } \\
\text { No liability: Employment not a material contributor to } \\
\text { injury/disease }\end{array}$ & 11 & 54 \\
\hline
\end{tabular}

What appears as a lack of clarity among employers, managers, regulators and insurers, not to mention workers, is what constitutes acceptable behaviour when disguised under the umbrella of management processes. Further, there appears to be a growing orthodoxy in which management tools, such as performance appraisals, performance management and improvement plans are employed as techniques for constructing an overriding narrative in which systemic victimisation is normalised and culpability is neutralised.

Complementing these cases are 54 claims heard by the Australian Industrial Relations Commission and Fair Work Commission (in 2006 to 2011) in which allegations centred on claims involving abusive behaviour over a prolonged period. This included bullying (41 per cent), intimidation ( 24 per cent), harassment ( 20 per cent) and assault ( 8 per cent). Issues of procedural fairness arose in many of these cases. A review of the decisions taken in these cases reveals the extent to which exclusionary arguments were employed to negate or otherwise justify abusive and injurious actions. Approximately one-third of cases involving claims of constructive dismissal - that the applicant had no option but to resign given the ongoing abuse - were upheld. Of specific import was the finding by both Commissions that organisational policies and procedures, from investigation to response to complaints, were consistently problematic. It was found that not only was there was a failure to comply with existing policies or procedures, but also there was deliberate misuse of such processes in a way that was judged to be unreasonable and unjust treatment of individuals. This manipulation of processes and abuse by systems was found to be present when the target of abuse was perceived as problematic. In examining the basis for Commission determinations, there is a discernible pattern: allocation of blame and individualising the problem were recurrent methods of justification employed to rationalise unreasonable and abusive management actions. Further, the Commissions rejected employer claims that requiring the victim to attend counselling and psychological treatment represented appropriate remedial action, suggesting instead that such requirements contributed to additional victimisation.

Across the various jurisdictions and determinations, it becomes evident that organisations can construct pragmatic motives for rule violation, which can then be aligned with the everyday routine and tools of organisational operations. This then leads to the normalisation and defence of actions that are not only inconsistent with not only the health and safety of workers, but also the intent of the regulatory framework itself. Importantly, such justifications 
are facilitated by the regulatory framework, which adopts a narrative that endorses and relies upon policy and process, rather than impacts or outcomes.

\section{Conclusion}

The dominant approach to regulating abusive behaviour within the workplace, which creates psychological injury, is problematic. Rather than acting as a preventative measure, the regulatory framework creates conditions that enable procedural injustice to occur. Three critical features of the current environment have been considered. The first is the foundation for determining compliance with the intent of regulation: the protection of workers from physical or mental injury or disease arising from abusive treatment. The focus on written documentation, policy and procedure, rather than outcomes, provides minimal incentive for organisations to introduce change. It also provides a basis for neutralising the injurious impact by employing management processes to abuse or deny procedural justice. Further, there is a pattern of organisations relying upon the exclusions from liability as set out in regulation, enabling the normalisation and neutralisation of abusive behaviour. In addition, the structural separation of regulatory action from the impact and outcomes for victims can be viewed as compounding the lack of justice. Finally, current approaches to enforcement or compliance in the face of a breach can be seen as broadly reflective not only of the responsive regulatory framework, but also of the extent to which such injury is viewed as a relatively low priority as a form of offending requiring remediation.

An alternative narrative would view the problem from the perspective of corporate culpability — with particular regard not only to the failure to prevent or respond to mistreatment, but in the wider duty of care. In order to challenge the existing orthodoxy in which management processes or culture are viewed as an acceptable basis for abusive behaviour, there must be a shift in prioritisation such that responsibility and liability for psychological injury cannot be avoided.

By aligning the intent of the regulation with the actions taken as part of routine enforcement, there would be a capacity to deliver direct procedural justice to the victim as an explicit component of regulatory involvement. Recognition of the injustice and injury that relies on the complainant going to a relevant court, commission or tribunal is likely to result in victims continuing to fall through cracks. While processes that separate insurers and regulators persist, there is undeniable risk that offending employers will continue to go undetected or unencumbered by compliance with the $M W H S$ Act. This then enables corporate abuse to continue relatively unfettered by ramifications for the individual victim.

Even these arguments are insufficient until the responsibility for abuse that results in psychological (and associated health, social, and financial) injury is recognised as being not simply a consequence of interpersonal conflict, performance management or organisational interests. It requires that the regulator recognises that organisations that enable or permit such abuse to fall under the radar using strategies of normalisation and neutralisation of offending behaviour are guilty of corporate malfeasance. This, in turn, requires a reflection on how to measure the effectiveness of the responsive regulatory framework - responsive to the organisation, to the victim and to standards of protection and justice.

\section{Legislation}




\section{References}

Ayres I and Braithwaite J (1992) Responsive Regulation: Transcending the Deregulation Debate, Oxford University Press

Bandura A, Barbaranelli C, Caprara G and Pastorelli C (1996) 'Mechanisms of Moral Disengagement in the Exercise of Moral Agency', Journal of Personality and Social Psychology 7(2), 364-74

Black J and Brown R (2010) 'Really Responsive Risk-Based Regulation', Law and Policy 32(2), $182-213$

Brief AP, Buttram RT and Dukerich JM (2001) 'Collective Corruption in the Corporate World: Toward a Process Model' in Turner ME (ed) Groups at Work: Theory and Research, Lawrence Erlbaum, $471-99$

Clarke MJ (2000) Regulation: The Social Control of Business between Law and Politics, MacMillan

D'Cruz P and Noronha E (2010) 'The Exit Coping Response to Workplace Bullying', Employee Relations 32(2), 102-30

Folger R (1987) 'Distributive and Procedural Justice in the Workplace', Social Justice Research 1(2), $143-59$

Giga SI, Hoel H and Lewis D (2008) Dignity at Work: The Costs of Workplace Bullying. Unite and BERR Partnership Program Project Working Together for Dignity at Work, Unite the Union/BERR

Hawkin K (1990) 'Compliance Strategy, Prosecution Policy and Aunt Sally: A Comment on Pearce and Tombs', British Journal of Criminology 30(4), 444-66

Hinds L and Murphy K (2007) 'Public Satisfaction with Police: Using Procedural Justice to Improve Police Legitimacy', Australian \& New Zealand Journal of Criminology 40(1), 27-42

Jenkins MF, Zapf D, Winefield H and Sarris A (2012) 'Bullying Allegations from the Accused Bully's Perspective', British Journal of Management 23(4), 489-501

Konovsky M (2010) 'Understanding Procedural Justice and its Impact on Business Organisations', Journal of Management 26(3), 489-511

Lutgen-Sandvik P and Tracy S (2011) 'Answering Five Key Questions About Workplace Bullying: How Communication Scholarship Provides Thought Leadership for Transforming Abuse at Work', Management Communication Quarterly 26(1), 3-47

Minor W (1984) 'Neutralization as a Hardening Process: Considerations in the Modelling of Change', Social Forces 62(4), 995-1019

Nelson ED and Lambert RD (2005) 'The Ivory Tower Bully's Vocabulary of Motives', Qualitative Sociology 24(1), 83-106

Pearce D (2006) Australian Workers' Compensation Law and its Application: Psychological Injury Claims, Safe Work Australia <http://www.safeworkaustralia.gov.au/sites/SWA/about/Publications/ Documents/104/AustralianWorkersCompensationLaw_ApplicationPsychologicalInjuryClaims_2006_ ArchivePDF.pdf>

Pershing J (2003) 'To Snitch or Not to Snitch? Applying the Concept of Neutralisation Techniques to the Enforcement of Occupational Misconduct', Sociological Perspectives 46(2), 149-78 
Piquero NL, Tibbetts SG and Blankenship MB (2005) 'Examining the Role of Differential Association and Techniques of Neutralization in Explaining Corporate Crime', Deviant Behavior: An Interdisciplinary Journal 26(2), 159-88

Productivity Commission (2010) Performance Benchmarking of Australian Business Regulation: Occupational Health \& Safery, Research Report

Safe Work Australia (2014) Psychosocial Health and Safety and Bullying in Australian Workplaces $<$ http://www.safeworkaustralia.gov.au/sites/SWA/about/Publications/Documents/857/Psychosocialbullying-statement.pdf>

Sutherland E (1949) White Collar Crime, Holt, Rinehart and Winston

Sykes G and Matza D (1957) 'Techniques of Neutralization: A Theory of Delinquency', American Sociological Review 22(6), 664-70

Thibaut J and Walker L (1975) Procedural Justice: A Psychological Analysis, Erlbaum

Tyler R (1989) 'The Psychology of Procedural Justice: A Test of the Group-Value Model', Journal of Personality and Social Psychology 57(5), 830-8

Yeager PC and Reed GE (1998) 'Of Corporate Persons and Straw Men: A Reply to Herbert, Green and Larragoite', Criminology 36(4), 885-97

Zoghbi-Manrique-de-Lara P (2009) 'Do Unfair Procedures Predict Employees' Ethical Behaviour by Deactivating Formal Regulations?', Journal of Business Ethics 94(3), 411-25 